\title{
A CATALYST OF CHANGE: A GRADUATE STUDENT'S PERSPECTIVES ON TRANSFORMATIONAL TEACHING
}

\author{
Ni-La L $\hat{e}^{1}$ \\ Michigan State University, USA \\ HCMC University of Education, Vietnam \\ José Martínez Hinestroza \\ Texas State University, USA \\ Erika B. Kraus \\ Michigan State University, USA \\ Azad Hassan \\ Michigan State University, USA \\ Nawroz University, Iraq \\ India C. Plough \\ Michigan State University, USA
}

\begin{abstract}
This article interprets teachers as change agents in light of the Transformational Teaching (TT) framework (Slavich \& Zimbardo, 2012). Contributing to the understanding of teachers' transformation, we report on a case study that explores how of a graduate student's conceptualization of and engagement with the core methods of TT emerged and developed through her teaching in the context of a locally situated Cultures and Languages Across the Curriculum program. The analysis offers three findings. First, the core methods of TT are evidenced in the teacher's practice. Second, specific program specifications facilitated her engagement with TT. Third, she was motivated to make changes in her teaching toward TT. We argue that the interaction among context, students, teaching practice and systematic reflection opportunities may act as a catalyzer of change in teachers' understanding and engagement with TT.
\end{abstract}

Keywords: transformational teaching; transformational teachers; graduate students; case study; Cultures and Languages Across the Curriculum

\footnotetext{
${ }^{1}$ The manuscript has two co-first authors: Ni-La Lê and José Martínez Hinestroza. Both are also corresponding authors. Ni-La Lê (lenila@msu.edu; 4835 Lago Vista Cir, San Jose, CA 95129). José Martínez Hinestroza (josemartinez@,txstate.edu; 601 University Drive, Education 3029, San Marcos, TX 78666).
} 


\section{Introduction}

Modern developments in education eschew the lecture-based classroom. Instead, contemporary pedagogical approaches such as active learning, student-centered learning, and experiential learning are growing as ways to increase student engagement and effective learning. Much research on these strategies addresses the teaching process and outcomes through students' point of view. Students' own preferences and moods could influence their perceptions; therefore, teachers' points of view as both providers of classroom material and intellectuals should also contribute to analyses of teaching approaches. Although scholars agree on the importance of promoting modern developments in teaching (Meyers \& Jones, 1993; Michael, 2006; Prince, 2004), methods and experiences from teachers about transforming their practice is an enduring matter that continues to puzzle researchers. Previous studies have explored how K-12 preservice and in-service teacher education programs help teachers transform their own practice (Cochran-Smith, 1991; DarlingHammond, 2006; Elliott, 2012). Less is known about systematic reflection as a form of professional development that may support graduate student's reconceptualization of teaching.

In this article, we address those issues by collaborating with a graduate student teacher-researcher (this paper's third author) in a case study to explore her own experiences, perceptions, and practice in a locally situated Cultures and Languages Across the Curriculum (CLAC) program. Throughout this exploration, we interpret the teacher, the graduate student, as a change agent considering the Transformational Teaching framework (Slavich \& Zimbardo, 2012). This framework suggests that teachers motivate and model transformations for students and for other teachers (Anding, 2005; Boyd, 2009; Rosebrough \& Leverett, 2011; Slavich \& Zimbardo, 2012). We ask the following research questions:

RQ1: How did a graduate student teaching fellow engage with the core methods of transformational teaching within this CLAC context?

RQ2: How did the teaching fellow conceptualize transformational teaching?

We argue that the interaction among context, students, teaching practice and systematic opportunities to reflect may act as a catalyst of change for teaching practice. Our study contributes a teacher's perspective on her efforts to transform her teaching approach. This perspective includes the teacher's reflections on her own practice, her context-specific repertoire of strategies, and her emerging conceptualization of transformational teaching.

\section{Theoretical Framework}

\section{Transformational Teaching: Definition}

Transformational teaching (TT) is a concept built upon contemporary approaches to learning and classroom instruction such as active learning, student-centered learning, collaborative learning, experiential learning, and problem-based learning. TT is driven by a combination of social cognitive theory, transformative learning theory, intentional change theory, and theories of transformational leadership (Slavich \& Zimbardo, 2012; Tahir, 2018). The term transformational teaching was first used by Slavich (2006) to describe the belief that instructors can promote meaningful change in students' lives if they view courses as stages upon which life-changing experiences can occur. A transformational teacher can "call ordinary students to embrace their own greatness" (Anding, 2005, p. 488). Characteristics of 
a transformational leader were found to be predictors of student engagement and satisfaction in English language learning classrooms in Pakistan (Tahir 2018). As transformational leadership helps students "see the larger view of education" and provides students with a "compelling vision of their future" (Boyd, 2009, p. 53), what underlines the TT approach is a notion of education being more about inspiration than information, and TT encourages instructors to equip students with both necessary skills and attitudes to successfully overcome challenges in real situations (Rosebrough \& Leverett, 2011). Significantly, within the TT framework, teachers not only facilitate transformation among their students, but they also show the desire to transform themselves. Thus, they serve as role models of motivation to change. Teachers engage with TT by entering a "fundamental state of leadership" in which they become results-centered, internally-driven, other-focused, and externally-open (Anding, 2005).

Slavich and Zimbardo (2012) describe three basic TT principles: (1) facilitating students' acquisition and mastery of key course concepts, (2) enhancing students' strategies and skills for learning and discovery, and (3) promoting positive learning-related attitudes, values, and beliefs in students (Slavich \& Zimbardo, 2012, p. 581). They argue that contemporary principles of learning and pedagogical methods can be considered as complementary components of TT and those three principles are their shared characteristics.

\section{Core Methods of Transformational Teaching}

Slavich and Zimbardo (2012) propose that TT involves the six following core methods. We provide a summary of why they are important in achieving the objectives of TT and how they can be employed in a classroom.

Method 1: Establishing a Shared Vision for a Course (abbr.: ESVC). Creating and continually promoting a shared vision of intellectual and personal growth throughout a course provides students and the instructor with a clear picture of their personal and collective future. This overall picture guides them in organizing their time, priorities, and expectations, and also generates intrinsic values and goals for which learning can be motivated and desired behaviors can be enacted.

An instructor can establish a shared vision for their course by either announcing or creating explicit goals of the course with input from students during the first meetings. While the former does not include the collaborative creation of objectives for the course like the latter, both techniques increase students' awareness of their responsibilities and collaboration in ensuring the vision is realized, and both require it to be communicated clearly and revisited frequently. The centerpiece of establishing a shared vision for any course is "to maximize students' chances for development by distributing the responsibility for intellectual and personal growth among all parties involved” (Slavich \& Zimbardo, 2012, p. 587).

Method 2: Providing Modeling and Mastery Experiences (abbr.: PMME). Transformational teachers provide modeling and mastery experiences that promote and transform students' attitudes, values, and beliefs about learning. They train students in applying critical thinking and problem-solving skills, and this can be done through encouraging students' direct engagement in the discovery process, inspirational motivation, and intellectual stimulation. At the same time, teachers model a wide variety of attitudes, values, and beliefs for their students. Pairing mastery experiences with social validation of personal efficacy (e.g., positive attitudes and beliefs in one's own abilities) is critical in maximizing the potential for the initiation of a transformational process. Instructors also need to ensure the responsibility for teaching specific skills and modeling of attitudes, values, and beliefs can be increasingly transferred to students, as this promotes mastery. 
Slavich and Zimbardo (2012) propose several ways to implement this method in the classroom. While framing problems as chances to practice and demonstrate specific skills, instructors can underscore that students have the personal capabilities and resources required to solve them. Teachers need to highlight that intellectual faculties can be improved with persistent engagement and practice (Dweck \& Master, 2009; Schunk \& Pajares, 2009). Another way is to create study groups where students confront challenges with peers who provide support, model new cognitive and problem-solving skills, and promote new habits of mind and different points of view (Mezirow, 2000; Taylor, 2007). These practices help students see difficult circumstances as challenges to overcome and opportunities to learn and to grow, instead of threats or barriers.

Method 3: Intellectually Challenging and Encouraging Students (abbr.: ICES). The practice of intellectually challenging and encouraging students is more than simply promoting acquisition of new materials. This core method emphasizes the importance of 'stretching' students' thinking and beliefs in order to transcend their own self-interests and achieve a higher level of functioning (Barling, Christie, \& Hoption, 2010; Bass \& Riggio, 2010)." This method is practiced by increasing the difficulty of questions and concepts as the course progresses. This ensures students understand concepts initially, and then utilize them to increase learning through challenges. Appropriate support is essential to this process so that students remain engaged and perceive themselves capable of meeting each challenge. This support is manifested in study guides, extended time intervals to complete work, and shared work with other students.

Other approaches to intellectually challenging and encouraging students include stating a goal, clarifying what skills and strategies students can rely upon to achieve the goal, and inspiring students with the confidence that they are capable. Making explicit the expectation that students will be challenged, while simultaneously framing these challenges as positive events to explore different perspectives, is another means of intellectually challenging students with appropriate encouragement and reinforcement (Slavich \& Zimbardo, 2012).

Method 4: Personalizing Attention and Feedback (abbr.: PAF). Personalizing attention and feedback is important to meet each student wherever they are in their personal beliefs, attitudes, and values about learning. Providing personalized experience must be balanced with establishing a shared vision for a course so that each student learns in a supportive, structured environment that promotes the three key principles of TT.

Personalized attention and feedback are essentially a setting where the teacher is others-focused. This means the teacher is aware and responsive to individual students' needs and abilities, as opposed to being driven by the goal of covering a certain amount of material regardless of students' personal goals, abilities, or characteristics, all of which differ among students. This method is observed when instructors use pre-assessments to learn how and where to challenge students and present material at the appropriate level. Personalizing attention and feedback is also evident when teachers work one-on-one with students to identify strengths, weaknesses, and areas of desired growth; then, teacher and student together develop plans accordingly, and the teacher provides targeted, constructive feedback to the student.

Method 5: Creating Experiential Lessons (abbr.: CELTBC). Experiential lessons that immerse students in a topic and transcend the boundaries of the classroom provide opportunities for students to experience concepts first-hand. Through these experiences, students gain a richer, more meaningful understanding of concepts and their operations in 
the real world, more positive beliefs about learning and about the self, and greater awareness of other people's experiences.

Creating activities to facilitate students' learning through experience and critical reflection makes the course content more interesting, and significantly improves students' memory of the key concepts as they are directly engaged in the whole learning process. Like other methods of TT, experiential lessons aim for attitudinal and behavioral changes. Interactive activities, like conducting social experiments or interviews with people in students' circles and community, are recommended as the most beneficial experiential lessons (Slavich \& Zimbardo, 2012, p. 593-594).

Method 6: Promoting Ample Opportunities for Preflection and Reflection (abbr.: PAOPR). Preflection and reflection, as reflective actions occurring prior to and after a concept, are critical for translating educational activities into meaningful, sustainable changes in students' lives and for enhancing their skills and strategies for discovery, which are both ultimate goals of TT. Preflection allows students to identify their (and their peers') attitudes and knowledge about a theme and to consider possible strategies for, or different perspectives on, tackling a problem; critical reflection afterwards provides students with opportunities to critique their own assumptions, revealing and deepening new concepts.

The process of examining one's thoughts and attitudes as preflection and reflection can be either public or private exercises through a wide variety of different forms: letters, guided reading, guided discussion, microlabs, structured debating, or fishbowl (Sullivan \& Glanz, 2009). In preflection activities, students can describe their attitudes or feelings toward and their past experiences with a specific topic or assignment, propose some strategies to examine or tackle the issue; and express the ways in which they expect the activity or experience will affect them (Shellenbarger, Palmer, Labant, \& Kuzneski, 2005; Van Merriënboer \& Sluijsmans, 2008). For reflection, students can share how their attitudes, beliefs, or perspectives changed, how they applied their capabilities, what strategies worked well, what aspects of the concept were challenging or compelling, what ideas they found most surprising or inspirational, what they learned about themselves through the process, and what they would do differently (Shellenbarger et al., 2005).

\section{Literature Review}

Transformational teaching approaches have been shown to lead to positive learning outcomes. Several empirical studies have concluded that students engaged in TT "demonstrate more learning, better conceptual understanding, superior class attendance, greater persistence, and increased engagement ... compared to when traditional lecturing is employed" (for a detailed review see Slavich \& Zimbardo, 2012). Additionally, TT significantly increases students' motivation and therefore has brought out enormous positive impacts on students' learning, such as performance and innovation (for a detailed review see Noland \& Richards, 2014).

Recent research continues to provide evidence of the advantages of TT. Fazio-Griffith and Ballard (2016) advocate applying the six core methods of TT in teaching critical skills for successful counselors. They argue that TT approaches provide experiences of emphasizing self-awareness, expanding worldviews, and providing personal insight that effectively create 'helping relationships' in professional counseling, and generate positive counseling encounters. Tahir (2018) also concluded that TT makes the classroom a learning experience, promoting creativity and independent thinking. The author claims transformational leadership traits, including charisma or influence, inspirational motivation, individual consideration, and intellectual stimulation, indicate a capacity to transform the 
classroom climate, resulting in improved communications accompanied by a deep understanding of concepts (Tahir 2018). Using student surveys, research shows that these transformational leadership traits identified in professors were positive predictors of student satisfaction in English language learning classrooms in Pakistan (Tahir 2018).

In addition to promoting better learning of key concepts and skills, TT has also been shown to generate a sense of responsibility and accountability in students and provide them with opportunities for valuable structured reflection (Breunig, 2017). In this study, students' understandings and experiences were explored through journals and focus groups from a fourth-year, student-directed experiential education elective course. In general, the students thought the professor's engagement and passion with the course and the "real life" commitment of the service-learning project design and installation impelled them to be more accountable. They also reported that participating in the study and engaging in structured reflection was impactful and that the experiential approach would have impacts on their future teaching and leadership.

A common and established means of understanding the effects of TT in most previous studies is through student reports (Maclellan, 2015). In fact, student evaluations of teaching to elicit diagnostic information are near universal (Maclellan, 2015). Potential issues are that student surveys elicit student preference for the course and/or instructor, rather than evaluate the teacher's capabilities in TT principles (Noland \& Richards, 2014), and in many cases student opinions about teaching do not correlate with achievement results (Maclellan, 2015). In addition, this approach fails to explore the intellectual experience of teachers who are inseparable from the climate of the classroom and have influences on students' experiences and transformation.

\section{Our Study}

As teachers are individuals "dedicated to the values of the intellect and the enhancement of the critical powers of the young" (Giroux, 2010), their thinking plays an important role in empowering learners to develop meaningful knowledge. Teachers' epistemic beliefs about the nature and development of knowledge are also significant aspects of teaching (Maclellan, 2015). Yet what teachers think of TT and of their teaching practices in terms of TT has not been sufficiently explored. Thus, we do not have a clear understanding of TT from teachers' point of view.

To address this missing piece in the TT research, our study aims to gain insights into a university teacher's perspectives on the core methods of TT in a second language teaching setting. We examine the case of a sixth-year graduate student who was a French teaching fellow (hereafter "the teaching fellow") in the Residential College in the Arts and Humanities at Michigan State University (hereafter "the College"). Through a case study analysis, we shed light on the teaching fellow's conceptualization of and engagement with the core methods of TT during an entire semester, within the context of the College.

Our report is organized as follows. In the methodology section, we first provide the context where both the teaching and the research took place: the College's Cultures and Languages Across the Curriculum (CLAC) program and one of its key components - the language immersion, project-based program called Integrated Language Options (hereafter 'ILOs'). We then briefly describe the teaching fellow who is the focus of our case study, the data generation, and our methods of analysis. We discuss three main findings and conclude by suggesting these findings indicate that teaching aligned with the core methods of TT is an agent of change as it fosters multiple transformations in teaching practice. We also interpret transformational teachers as agents of change themselves in the sense that they take 
the initiative to adapt TT in ways that are consistent with their students' needs and the learning objectives.

\section{Methodology}

With the purpose of understanding the teaching fellow's perspectives on TT, we adopt a case study methodology to develop insights into her experiences. Consistent with characterizations of case study as a bounded system that is an instance of a phenomenon of interest (Merriam, 1998; Yin, 1994), we define our case as a teaching fellow engaging in TT in the context of a language immersion, project-based CLAC program. The teaching fellow filled the roles of teacher and co-researcher, engaging with the rest of the research team in making sense of her perspectives and practices related to TT. We first share a description of the CLAC program and then introduce the teaching fellow and our rationale for focusing on her experiences.

\section{The Context}

CLAC programs offer opportunities for students to use their knowledge of cultures and languages beyond the language classroom (Adams, 2000; Davies, 2012). CLAC programs complement traditional language instructions by extending the use of languages to multiple meaningful contexts (Rifkin, 2012). With this purpose in mind, instead of following one rigid format, each institution creates a CLAC program that is responsive to the local context (Plough, 2016).

One of the key components of the College's CLAC program are ILOs, which are grounded in sociocultural theory and a social interactional theory of second language acquisition (Lantolf, 2011; Lantolf \& Thorne, 2007). ILOs are semester-long, language immersion, project-based collaborations among graduate student teaching fellows and undergraduate students. The number of students in an ILO has ranged from one (e.g., Vietnamese ILO) to 15 (e.g., Spanish ILO).

ILOs require students to use receptive and productive skills in the target language and engage in extended, meaningful interaction. Using a range of communicative functions in the target language, students collaborate with peers to decide on a theme, and then develop and create a final product. The project-based approach of ILOs provides students with realistic input and promotes learning by doing - learning aspects of the linguaculture as well as specific knowledge and skills required of the project. Students have created videos, posters, and websites in which they examine discrimination and human rights for members of the Deaf community in the U.S.; issues of poverty and privilege in the educational system of Colombia; the portrayal of family, war, and peace in Korean cinema; and perspectives on transitional justice among Arab Spring activists. The projects on which ILOs focus are determined by each group. At the end of the semester, all ILO products are shared in a public showcase with peers, family members, and the wider community.

Teaching fellows employ a process of reverse development in planning their ILOs. Once the topic and product are selected, fellows ask a series of questions: What is the context and who is the audience? What are the necessary steps to completion (e.g., knowledge and skills required)? What language (e.g., grammatical, lexical, interactional) is required? Finally, what tasks and activities focus on the necessary skills and required language? During each ILO meeting, the teaching fellow and the students engage in communicative tasks that help them develop the necessary knowledge, skills, and language. These tasks also include a collaborative development of the final products.

The teaching fellows who participate in the CLAC program are (near) native speakers 
of a world language in addition to English. They come from different disciplines and are not necessarily familiar with the College, CLAC, language immersion, and project-based teaching and learning. In addition to facilitating ILOs, the teaching fellows also participate in weekly professional development seminars in which they and the CLAC program director discuss topics ranging from the scholarship of teaching and learning to specific issues emerging in their ILOs or the CLAC program more generally. Toward the middle of the semester of this research, two of the weekly seminars included discussions about TT. The teaching fellows read the article by Slavich and Zimbardo (2012) and discussed what they understood TT to be and how their work in the ILOs related to the core methods of TT. Beyond these discussions that focused on TT, interactions around the core methods occasionally emerged in the weekly seminars. These interactions tended to focus on the similarities that TT seemed to have with the ILOs, including the relationship between the collaborative nature of ILOs and the TT core method of establishing a shared vision. Each teaching fellow, however, decided how explicit to be in the incorporation of TT in their respective ILO. There was no explicit modeling or training on how to enact core methods in the ILOs. Teaching fellows did not explicitly discuss TT with the undergraduate students in their ILOs.

\section{The Focal Teaching Fellow}

The focal teaching fellow is a white, American female who is a native speaker of English. She is a near-native French speaker. Her process of learning French began as an undergraduate student and continued during her three years as a United States Peace Corps volunteer in Benin, West Africa. At the time of this research, she was in her sixth year of graduate school in Forestry. She had previous experience teaching undergraduate students in Biology, Forestry, and French, all in text- and lecture-based classrooms. Her previous French language teaching experience did not involve language immersion, project-based learning or methods of TT.

\section{Case Study of Focal Teaching Fellow}

Our decision to focus on this teaching fellow is based on two main considerations. First, some key characteristics and experiences of this teaching fellow are typical of the graduate students who participate in the CLAC program. For example, the teaching fellow's process of learning an additional language involved traditional language classes and experiences of language and culture immersion abroad. She also had not had preparation or experience related to project-based language teaching. Second, at the moment of data generation, the teaching fellow was in her first semester in the CLAC program. Focusing on her perspectives and practices helped us examine the learning process for a person exposed to ideas of TT for the first time.

We follow tenets of heuristic case studies (Merriam, 1998) with the purpose of shedding light on these interrelated issues: (1) the evidence of the teaching fellow's engagement with the core methods of TT, and (2) the contextual factors that the teaching

fellow identified as influential in how she learned about and enacted TT. Exploring these issues from the perspective of a teaching fellow is consistent with case study's attention to local and situated forms of knowledge in a unique context, such as the one that the CLAC program offers for graduate students to engage with TT.

\section{Data Generation}

We draw on four sources of data: (1) teaching fellow-provided notes and/or plans she used for each ILO meeting throughout a semester, (2) a self-reflection questionnaire 
completed after each ILO meeting, (3) a video recording of one ILO meeting and the notes the research team generated during the first round of viewing the video, and (4) an interview between the teaching fellow and the rest of the research team to discuss selected portions of the video recording.

ILO meeting plans. Throughout the fall 2017 semester, the teaching fellow provided plans for each meeting with the French ILO students. We draw on these plans to explore potential involvement with the core methods of TT, and to consider the plans in relation to the self-reflections. These data helped us identify recurring themes in TT-related lesson planning.

Self-reflection questionnaire. The questionnaire had 12 open ended questions (See Appendix). The teaching fellow answered them after each meeting with students. The researchers developed these questions with the aim of eliciting the teaching fellow's perspectives on TT in relation to her teaching throughout the semester. The total time commitment to complete the questionnaire was approximately 2.5 hours over the course of the semester.

Video record of ILO meeting. The video provided first-hand observation of a typical ILO meeting, in addition to the meeting plans and self-reflections. This data source was used to establish which core methods of TT the teaching fellow effectively engaged with and how those core methods appeared.

Retell notes and interview on the video recorded ILO meeting. The video recorded ILO meeting was reviewed in three rounds, which will be detailed in the data analysis section below. Retell notes were generated individually by each researcher during the first round of viewing. The notes included suggestions on the timestamps of that ILO meeting, possible evidence of TT, and any other noticeable details. A week after, the research team interviewed the teaching fellow about the video recorded ILO meeting. The purpose of this discussion was to elicit the teaching fellow's interpretation of TT in that ILO meeting. We audio recorded and transcribed this interview.

\section{Collaborative Data Analysis}

The data generated and described above were analyzed by the teaching fellow and the other researchers independently, in pairs, and in groups. For each analysis step, the research team met to set goals and design coding sheets. We elaborate on each analysis next.

First, the researchers reviewed the data independently and interpreted multiple core methods of TT in each data source. When needed, the teaching fellow interpreted the French used in her plans. Then, the research team collected their coded data to examine the interpretations of core methods in each data source with respect to each core method. Finally, the entire team engaged in iterative cycles of coding comparison and discussion. Rather than conducting a traditional analysis of intercoder reliability or seeking agreement in the codes where there was initial disagreement, these iterative cycles focused on collaborative cointerpretation to make sense of the entire data set. This collaboration allowed us to generate robust analyses that considered the multiple alternative interpretations that each researcher had about how the teaching fellow engaged with the core methods of TT and her conceptualization of TT.

The ILO meeting video recording, the retell notes, and the interview entailed three rounds of viewing. The research team identified instructional episodes, or class moments beginning with a change in instructional method or focus (Farran \& Bilbrey, 2004). During the first round of viewing, the research team watched the recorded video while making general annotations of what was salient, including timestamps of possible episodes for further 
analysis. During the second round of viewing, the research team members coded instructional episodes for evidence of one or more core methods of TT. The teaching fellow conducted these rounds on her own after the interview. During the third round of viewing, the teaching fellow and the rest of the research team watched the video and conducted open coding of specific instructional strategies interpreted as conducive to a core method of TT.

Our analysis focused on qualitative interpretations of how the teacher engaged with the core methods and how she conceptualized TT, as we discuss in the next section. We did not focus on the number and frequency of core methods that the teaching fellow planned for or enacted, though this data supports our interpretations.

\section{Findings}

In this study, we are interested in how and to what extent the teaching fellow's engagement with and conceptualization of TT emerged during her first semester participating in a project-based, language immersion teaching model. Our co-interpretation of the data highlights not only how she engaged with TT, but also her explicit opinions on how the CLAC program has oriented and shifted her teaching practice toward a more TTlike approach.

Our analysis offers three major findings. First, the core methods of TT are evidenced in the teaching fellow's practices in her ILOs. Second, her engagement with these core methods stemmed naturally from her understanding of the ILO specifications and weekly seminars. Third, while reflecting, she expressed a strong intrinsic motivation and agency to make changes in her teaching toward TT. We list the TT core methods below, for readers' reference, and throughout the next sections we reference them by short abbreviations.

1. Establishing a shared vision for a course (ESVC)

2. Providing modeling and mastery experiences (PMME)

3. Intellectually challenging and encouraging students (ICES)

4. Personalizing attention and feedback (PAF)

5. Creating experiential lessons that transcend the boundaries of the classroom (CELTBC)

6. Promoting ample opportunities for preflection and reflection (PAOPR)

\section{Evidence of the Core Methods of TT}

In this section we address the first research question: How did a graduate student teaching fellow engage with the core methods of TT? We present the research team's cointerpretations of these core methods in the teaching fellows' ILO meeting plans, selfreflections, and the video recorded ILO meeting.

Tables 1 and 2 provide examples of the co-interpreted core methods of TT from the teaching fellow's ILO meeting plans and self-reflections. Because the teaching fellow kept her meeting plans in French, we offer an English translation in Table 1. The self-reflections were completed in English. As evidenced through these data sources, most meetings had multiple core methods co-occurring in various combinations. Of the semester's ten ILO meetings, there were three in which only one method was co-interpreted as occurring: in two meetings, only method ESVC emerged; in a third meeting, only method PAOPR emerged. Methods PMME and ICES emerged as substantive core methods throughout her ILO meetings. Methods PAF and CELTBC were co-interpreted as occurring in conjunction with other core methods, never in isolation. 


\section{Table 1. Meeting plans coding examples}

Example from ILO meeting plans_-English

Core method

Collaborative project discussion

ESVC

I present myself; the students present themselves

PMME

Starting with plants: an introduction to plants in the Plant and Nature

ICES

Garden (JPN). Foundational information: history of JPN as sacred forest for the kingdom, $f a$ consultation, execution site, colonial construction and no longer sacred. "Zoom on the Iroko" booklet from JPN: read the first sentences of each paragraph together, then in partners; then two paragraphs per partners. Each individual provides a summary of the reading.

Questions: How is Iroko part of Vodoun? What is a current problem for the Iroko?

Look into: African hyssop tree, mombin tree

Self-presentations, repeat information for new participants, ask a new question for everyone

Present my life and experiences in Benin: many photos, many questions.

CELTBC

Think again: how does participating in this ILO affect your life?

PAOPR

The ILO video recorded meeting, which represents a typical ILO session between the fellow and undergraduate students, is the third data source for this research. The research team co-interpreted the core methods of TT, listed in Table 3, for the teaching episodes identified in the video recording.

\section{Table 2. Self-reflections coding example}

Example from self-reflections

Core method

All the students have agreed that studying the traditional religion is ESVC interesting to them. Today the students listed different aspects of studying a religion, and then they researched those aspects.

I partnered the more advanced student with the least advanced in the comprehension activity. The most advanced also readily gives answers, but today I had to make a point of asking other students for their responses, too.

... engaged by reading, and answering questions... I designed the session to ICES be that way, but they were tired and not being very creative. I think they were just tired.

We've been studying the traditional religion and I bring things to them about that religion. Their personal interests, well, I don't know. One student likes learning about plants, and we've covered that some. Another student wants to know more about reciprocal effects of one cultural on the other, and I'm trying to work that in, too.

PMME

PAF 
Example from self-reflections

Core method

With videos, texts, of Vodoun gods and the religion in 'real-life' in Benin.

CELTBC

I like to think that the students are developing a positive image about the

PAOPR religion of Vodoun and how people live their lives, or if not positive at least a more informed point of view about life in Benin.

Throughout the video recorded ILO meeting, there were points where the research team interpreted the teaching fellow engaging with multiple core methods of TT simultaneously, and other moments where core methods of TT are identified in isolation. Like the ILO meeting plans, method ICES proved to be a substantive component of the meeting, along with methods PMME and CELTBC. There were four moments where one core method is co-interpreted: method PAOPR at the beginning and the end of the meeting, method PAF at a mid-way point for a pause (yoga break), and method ICES when students reported back on research about the uses of trees. The research team did not co-interpret any teaching episode of the video recording as core method ESVC.

Table 3. Teaching episodes co-interpretation

Focal teaching episodes

Identified

core methods

ILO members' comprehension/comfort self-evaluation

PAOPR

1 st view of content-related video/review of video

PMME, ICES

2nd view of content-related video/review of 2 nd view with mini history

lesson

PMME,

CELTBC

Lesson with written text

PMME, ICES, CELTBC

Discussion of text, yoga break

PAF

Review of previous meeting

ICES, CELTBC

Sharing of research on tree use

ICES

Return to reflection from beginning of meeting

PAOPR

\section{Teaching Fellow's Conceptualization of Transformational Teaching}

In this section we address the second research question: How did the teaching fellow conceptualize TT? Our data sources are the retell notes of the video recorded ILO meeting, the transcript of the interview, and the self-reflections. As such, we consider the fellow's selfreported conceptualization of TT expressed through reflection and dialogue. Our analysis of her sharing then suggests the teaching fellow's conceptualization of TT included characterizing TT as a theoretical construct separate from her practice (as a theoretical discussion in the weekly fellows' group meeting). Subsequently, through dialogue her 
characterization moved toward a situated interpretation of TT as it emerged in her ILO (identifying her teaching practice in the ILO as TT core methods). Moreover, features of the ILOs and the CLAC program influenced how the teaching fellow refined her conceptualization and then connected it to her practice. We illustrate this finding with quotes from the teaching fellow's self-reflection during her first semester of involvement in the program and with quotes from the interview during her second semester in the program.

Questioning engagement with TT. In her first semester in the CLAC program, the teaching fellow initially conceptualized TT as a theoretical construct separate from her practice. Although the teaching fellow was aware of TT principles and core methods from the discussions in the weekly seminars, she was unsure about the extent to which she was engaging with these principles and core methods in her ILO meetings. When discussing how she planned her meetings with students, the teaching fellow stated that she did not plan "based on [TT] core methods... they were not in the forefront of my planning." This insight was present both when the teaching fellow referred to her practice in general, and when she referred to specific examples, as detailed next.

Initially (during her first semester in the program), the teaching fellow readily identified core methods PMME, ICES, and PAF as essential to an ILO, but put a caveat on method PAF because she "hadn't had a group [of students] of 10 or 12." She treated core method PAOPR as a potential component of ILOs, saying she could "... make [preflection and reflection] a habit" and referenced discussion in some of the weekly seminars. The teaching fellow treated core method ESVC with uncertainty, saying "[ $[$ Method ESVC $]$ would be something you would want to revisit... but maybe it's something you'd want to focus on for a while and then cycle around to it." She demonstrated uncertainty about the core method CELTBC, seeing it as a potential component of an ILO by saying "Probably if I knew how to do [method CALTBC] better." However, she also reported, "If experiential lessons is [sic] more like what we [in the fellows' weekly seminar] have been talking about in terms of taskbased, then certainly I could see that happening every day." In a follow-up question, the fellow talked more about method CELTBC as difficult to engage in, again demonstrating her unfamiliarity with that method. She said: "I wasn't hitting a lot of the senses, just listening and speaking."

The teaching fellow's initial conceptualization of TT as a theoretical construct separate from her practice was also evident with other core methods. For example, the teaching fellow discussed how her group developed an interest in religions in Benin. One of the activities the fellow reported involved describing pictures of the teaching fellow's experiences in Benin. As the group made sense of the images, her students posed questions about religion in this context. Through different conversations, it became clear to the fellow that the group wanted to know more about this topic. In her weekly self-reflection, the fellow wrote:

I like to think I modelled two things: describing without knowing the perfect language to express it perfectly, hence the repetitions; and two, asking questions of something pretty unfamiliar. For example, in the traditional religion there is a divinity of a formidable illness, and I really wonder why that is the case.

Similarly, when asked about the collaborative development of this topic as the theme of the ILO, the teaching fellow noted: 
I didn't think of that [establishing a shared vision of the course] at the moment... I wasn't necessarily trying to intellectually challenge them, but I wanted to know... 'are they thinking about it? Is it interesting to them?' So I wasn't necessarily like trying to intellectually challenge them.

The teaching fellow acknowledged the relationship between this example and the core methods of TT of establishing a shared vision for a course and providing intellectual challenges. However, she reiterated that at the moment of planning and teaching, she had not been intentional about engaging with those core methods.

As the teaching fellow described her ILO meetings during the interview (which occurred after the first semester ended), however, she began to interpret some of her practices as possible evidence of engagement with the core methods of TT. For example, when describing how she used circumlocution and drawings to express ideas, the teaching fellow discussed how one of the students followed this same practice. Instead of resorting to English or giving up when she did not know how to communicate an idea in French, the student mimicked the teaching fellow's practice and went to the board to use drawings to support communication. Summarizing this instance of her practice, the teaching fellow stated: "I wanted the students to think that they can do that too... I don't know if that really counts as modelling." Although the teaching fellow described her intent of this practice as a way of providing modelling (method PMME), she initially cast doubt on its relationship with the core methods of TT.

TT and CLAC specifications. When the teaching fellow and the rest of the research team engaged in dialogue about her teaching and insights on TT, the teaching fellow communicated a conceptualization of TT within the CLAC program specifications. These specifications involved language immersion and the project-based approach, and the learning community the CLAC program provided, including this research project. As the teaching fellow put it during the interview, "the TT is probably behind a lot of what I was being told about how to conduct an ILO, but I was not familiar with these specific core methods of TT... I was trying to do the ILO thing." She also commented on how the core methods she considered most essential to an ILO occurred frequently throughout the semester, focusing specifically on method ESVC. This suggests a strong sense of how she structured and conducted her meetings in a way that aligned with the College's CLAC ILO program goals, and that this type of structure came to align with her ideas about TT.

One of the features of ILOs that the teaching fellow identified as supporting the emergence of the core methods of TT was the collaboration among students and the teaching fellow in deciding on a product to showcase their work. When talking about how her ILO decided to create a tunnel box as their final product, the teaching fellow stated:

[Through] the ILO way of like teamwork, collaborating, everyone definitely contributed. And I really liked that it [the product] was a tangible thing... I like the idea of representing your thoughts in a concrete way, so they could look at each element in that tunnel box and say 'that relates to this, and that relates to this...' We all worked together to choose what went into the tunnel box, worked together to make the stencil that cut out the pieces, worked together to glue it together. [That], helped in their reflection too and being able to look back on it and be like what does this all mean? 
This statement relates to establishing a shared vision as the students and the teaching fellow co-developed the idea of what the product would be. It also considers fostering reflection as the students and the teaching fellow used the product as an artifact to ground their thinking about what they had learned. Unlike the examples in the previous section, in this case the fellow explicitly acknowledged the evidence of these core methods in her practice. Thus, we interpret it as evidence of an articulation of what TT meant for her.

The language immersion approach that characterizes ILOs also influenced the teaching fellow's conceptualization of TT. She saw the use of the French language as an intellectual challenge for students. Additionally, considering that the language immersion approach involves task-based experiences, the teaching fellow related language with method CELTBC:

The creating experiential lessons... would probably depend on the language level too... if that experiential lesson is more like what we [language fellows] have been talking about in terms of task-based, then certainly I could see that [engaging with experiential lessons] happening every day.

The structure of the ILOs related to language use influenced the teaching fellow's conceptualization of TT as infused in her task-based approach.

An additional feature from the ILOs that the teaching fellow described as supporting her involvement with TT was the weekly seminars where all fellows discussed ideas related to the CLAC program. The teaching fellow mentioned the example of how the weekly seminars had focused on what it means to reflect and how to support student reflection. The fellow stated:

A lot of them [core methods of TT] can be done, like the preflection and reflection, a person can get in the habit of doing some form of that. I mean, we [all language fellows] have been talking about it now. We don't know what it is or how to do it but we could probably develop some way to make that habit.

In this case, she conceptualized TT as integrated with her efforts not only in the ILOs but also in other components of her participation in the CLAC program, specifically the weekly seminars.

Transforming experience for students. A dimension of the teaching fellow's conceptualization of TT was her explicit interpretation of the ILO experience as transformative for students. As the teaching fellow put it:

I think [students' biggest take away] would be the relevance of that particular site and the plants that were there both in how people used plants, in particular trees, like they can be very physiological and healing... but also how those trees represent things like spirituality and how that particular site is one case study of the Vodoun religion.

Thus, the teaching fellow perceived that students learned about the specific content of the ILO (i.e. religion in Benin).

Additionally, the teaching fellow regarded the ILO experience as fostering students' transformations of beliefs they held about the topic: 
I think they [the students] were all originally interested in the religion just as an exotic... One student said 'I thought Vodoun was like essentially what Hollywood portrayed it as, and I learned that this is a real thing, a real religion that people... [that $]$ affects them.'

Moreover, the teaching fellow interpreted students' transformations of what they thought about Vodoun as broadening their understanding: "I think that definitely the way I would describe [the ILO] would be a broadening... a broadening of understanding of this human place in the world."

Finally, the teaching fellow recognized her own role as an agent of change, provoking students' transformations: "I provoked this by asking them [the students]... 'What is Vodoun?' ... one student remarked, 'well, this is like saints in Catholicism'... and the other student joined in and shared... she thought it seemed like any other religion, too." The teaching fellow interpreted this example of the core method of reflection as a way to bring awareness of and transform perceptions of Vodoun.

\section{Teaching Fellow's Self-Transformation}

While the first and second findings address the teaching fellow's engagement with and conceptualization of core methods of TT, respectively, this section discusses the influence of that engagement and the conceptual development on her teaching. In particular, we find that while reflecting on her teaching as part of this CLAC program, the teaching fellow expressed intrinsic motivation and agency to move away from lecturing practices and make changes toward the TT approach.

Throughout the interview and the weekly self-reflections, the teaching fellow often expressed her caution that she should stay away from lecturing and kept questioning herself if she might still be doing that. For example, after the third ILO meeting, she was concerned about her students' ownership and that she was "still 'teaching' too much." When reflecting on the sixth meeting, she answered 'no' to the question of whether her students shared their attitudes or feelings toward a cultural issue in that meeting and went on to take responsibility for that, saying "I suppose I should ask more questions. I still feel very 'teacher'-y."

When asked what she meant by "teaching" or "teacher-y", she explained that she felt like for the first few ILO meetings, she was unexpectedly still lecturing and talking too much, instead of facilitating, motivating, and having students talk more in task-based activities. This supports the claim made above that the teaching fellow knew she should not treat ILOs as a traditional classroom, but at the same time her ideas and conceptualization of ILOs and of TT were still developing. She acknowledged this challenge explicitly during the interview:

I wasn't ever totally sure that I was presenting material in a very ILO way. I kinda felt like I was doing a course, and that I was talking a lot, I was presenting a lot of information, trying to make it more of an experience was harder for me.

Later, she shared her struggle to get students to share their thoughts and reflections on what they had learned (i.e., method PAOPR of TT):

I had planned to ask them the question but I didn't know what all would come of it, about how they had applied what they'd been learning in the ILO to their 
own life. [...] I wanted to know what they were thinking, but I didn't know how to ask.

Driven by this concern, the teaching fellow paid close attention to her students' positive changes as a type of feedback for her teaching, which again shows her (unintentional) engagement with TT, given one of the key principles of TT is to promote students' transformation. In particular, she noticed and was excited whenever the students showed initiative to acquire knowledge and skills. In the self-reflection for the fourth ILO meeting, responding to the question of whether "students propose strategies for examining an issue or tackling a problem during discussions," the teaching fellow stated:

YES! Finally. One student proposed a project doing sculpture or art of some kind, and the more advanced student, who likes the 'nature' part, suggested combining the representation of the divinity with some other aspect related to the divinity, like things of nature it might need, or food it prefers, etc., to round out our information of the divinities and make describing them more interesting.

For her, it was also very important that her students can "better, more freely, express themselves." And as already mentioned, she set broadening her students' point of view as another goal of their ILO discussions. We interpret the fellow's setting of such objectives as an indication of her conceptualization, influenced by the ILO's structure and attention to TT.

Such self-awareness of what was going on in a classroom, which areas a teacher needed to develop, and what they would want to happen - as discussed above-is a starting point of any change. However, a change cannot happen without motivation, plans, and actions. In this case, the teaching fellow demonstrated herself as a change agent by showing strong motivation to change the way she teaches, putting some thoughts on how she could change, and then acting upon them.

The teaching fellow's efforts to take actions to change are exemplified through her self-reflection for the fourth meeting. Recall that the teaching fellow felt she was still teaching in the previous meeting. In the fourth meeting, however, she revealed that she tried "to keep the materials and activities in their [the students] interests." She continued by admitting, "I am not yet very adept at creating activities," but she did "repeat, repeat, repeat, with different ways of telling, until [she was] satisfied the students appear to be understanding". She also shared that at the beginning of the meeting, she worried that she might be "just going to bore" the students but later felt relieved that it was not the case:

I [would] like to think that maybe I found a good way of sharing something about the religion (more personal stories), as well as having covered enough material to introduce them to the religion, that helped the students contribute today to what they would want to do.

During the interview, the teaching fellow also mentioned a couple of times what she could do differently to ensure her lessons were less 'lectur-y' and/or were more connected to some specific methods of TT. For example, addressing her concern that the video recorded ILO meeting was not experiential, the fellow proposed some ideas of what an experiential lesson would look like for the same topic: 
It would be interesting to go to like the [campus botanical] garden and look at those plants and maybe talk to a botanist and you know, actually hear from a botanist the specifics of how plants can be used, and that would be much more of an experience, plants would be right there that they could touch and feel and learn about and understand different traits of plants that relate to medicine. [...] I could have brought some plants in.

Our third finding offers some insights into the teaching fellow's perspective of the transformation of her own teaching. As teacher transformation is a desired outcome of TT (Slavich \& Zimbardo, 2012; Telsang, 2015; Vetter, 2012), the teaching fellow's selftransformation as shown is another piece of evidence for her engagement with TT.

\section{Discussion}

A case study approach has provided a rich description of a teaching fellow's initial engagement with TT, her process of conceptual development and application of core methods of TT, and key contextual factors that supported her throughout the experience. Based on a collaborative analysis of the descriptive and qualitative data generated by this method, our study offers some insights into a teacher's perspective on her engagement with and conceptual development of TT in general and its core methods, in particular. We found that the teaching fellow's meeting plans, self-reflections, and observations from a video recording of her teaching are evidence of her engagement with all core methods of TT. We also showed how the teaching fellow's conceptualization of TT came to encompass both the abstract and the applied through her experience in the CLAC program.

This study also describes what the core methods of TT look like in practice and suggests ways in which TT unfolds. Although the teaching fellow reported not purposefully engaging in core methods of TT, she effectively incorporated them into her meetings. In her first semester in the CLAC program, she understood her role most clearly in what she should not do; that is, she understood she should not be teaching a 'traditional' language text-based course. Her development in formulating ideas about what she should do decreased in abstraction through her interactions with other language fellows in the seminar and her ongoing implementation of the ILO. In other words, her transformation was influenced by the TT approach inherent to the ILO structure. The data thus highlight the important role of the ILO design and the learning community the CLAC program provides (including its unique teacher-student dynamic and systematic reflection opportunities) in the emergence, development and refinement of teachers' understanding of and engagement with TT. From that perspective, this CLAC program exemplifies an effective and creative approach in facilitating the self-transformation of graduate students as future teachers and researchers.

Our findings confirm that teaching as a multi-component process is an agent of change in the sense that it fosters multiple transformations. First, the case study suggests evidence of multiple aspects of the teacher's self-transformation throughout her engagement with TT, including the transformation of teaching concepts, objectives, plans, and teaching practices. This transformation was connected to the way in which ILOs and the CLAC program are designed. Second, we have shown that the interplay among the teaching fellow, students, program specifications and context, and teaching approaches, specifically TT, fostered these multiple transformations. In other words, as each change in the reflectionmotivation-plan-action circle may provoke a domino effect on the fellow's teaching, the transformation of any of the interdependent aspects of teaching may provoke changes in teaching in general. 
Indeed, the teaching fellow explicitly shared how the language immersion, projectbased ILO model and the CLAC's weekly seminars where teaching practices and theories (including TT) were discussed among peers and education experts oriented her towards making productive changes in the way she taught. In addition, teaching the French ILO influenced her perceptions of what student learning and understanding mean and what she could do to align with the TT framework. This, in turn, fostered changes (or intentions of change) in her practice and students' attitudes (as perceived by the fellow). The weekly seminars and the CLAC program have also evolved over time to embrace and encourage those changes in teacher's perception and practice. It is also important to point out, then, that while teaching promotes changes to specific teaching-related factors, each factor can act as an agent of change for other factors and for teaching in general.

\section{Conclusion}

Our study has implications for both research and teacher education. In terms of research, this study illustrates a way of drawing on TT not only as a framework to guide pedagogy and teachers' professional development, but also as a theoretical framework that can inform the exploration of educational issues. Specifically, our findings advance understanding of TT as a framework that can help researchers explain teaching processes that, in contrast with traditional language teaching contexts, are characterized by responsiveness, co-development of experiences among teachers and students, and a focus on active learning. Additionally, our study has methodological implications. By involving a teacher as a researcher analyzing data and grounding our exploration on previous research, our findings are relevant not only to scholars but also to teachers. Engaging in research around their own practice constitutes a form of reflection in and of itself, that gives teachers opportunities to further refine both their research and their teaching. Similarly, by engaging in collaborative data analysis with the teacher-researcher, our findings go beyond member check methods traditionally used in qualitative research. Beyond confirming or disconfirming researcher-generated analyses, this collaboration helped us consider possible interpretations and context-specific influences that otherwise would have been unlikely to emerge. In terms of teacher education, our study contributes to understanding the under-explored issue of learning to teach in transformative ways in higher education. Taken together, these theoretical, methodological, and practical implications call for more studies where the interplay between research and teaching is transformative for all participants.

As research on transformational teaching continues to explore what it is, and what it is not, this paper advocates for rich empirical studies, especially from the teacher's point of view, as an effective means to understand how teachers can (be supported to) engage with this pedagogical approach. Such studies would also contribute to the evaluation of the principles and core methods of TT both theoretically and practically, based on which innovation can emerge and positive learning outcomes can increase.

\section{References}

Adams, T. M. (2000). Languages across the Curriculum: Taking stock. In M-R. Kecht \& K. von Hammerstein (Eds.), Languages across the curriculum: Interdisciplinary structures and internationalized education (pp. 15-38). Columbus, OH: National East Asian Languages Resource Center.

Anding, J. M. (2005). An interview with Robert E. Quinn entering the fundamental state of leadership: Reflections on the path to transformational teaching. Academy of Management Learning $\mathcal{E}^{2}$ Education, 4(4), 487-495. 
Barling, J., Christie, A., \& Hoption, C. (2010). Leadership. In S. Zedeck (Ed.), APA handbook of industrial and organizational psychology (pp. 183-240). Washington, D.C.: American Psychological Association.

Bass, B. M., \& Riggio, R. E. (2010). The transformational model of leadership. In G. Robinson Hickman (Ed.), Leading organizations: Perspectives for a new era (2nd ed., pp. 76-86). Thousand Oaks, CA: Sage Publications.

Boyd, B. L. (2009). Using a case study to develop the transformational teaching theory. Journal of Leadership Education, 7(3), 50-59.

Breunig, M. (2017). Experientially learning and teaching in a student-directed classroom. Journal of Experiential Education, 40(3), 213-230.

Cochran-Smith, M. (1991). Learning to teach against the grain. Harvard Educational Review, 61(3), 279-311.

Darling-Hammond, L. (2006). Constructing 21st-century teacher education. Journal of Teacher Education, 57(3), 300-314.

Davies, D. (2012). How to design \& implement a CLAC program that works for your campus. CLAC 2012 Conference, The University of Minnesota. Cited in What Does an Internationalized Curriculum Look Like? The Promise of Cultures and Languages across the Curriculum. NAFSA Webinar Handout (2013, February 27).

Dweck, C. S., \& Master, A. (2009). Self-theories and motivation: Students' beliefs about intelligence. In K. R. Wentzel \& A. Wigfield (Eds.), Handbook of motivation at school (pp. 123-140). New York, NY: Routledge.

Elliott, J. (2012). Introduction. In J. Elliott (Ed.) Reconstructing teacher education (pp. 1-14). New York, NY: Routledge.

Farran, D. C., \& Bilbrey, C. (2004). Narrative record observation for classrooms. Nashville, TN: Peabody Research Institute, Vanderbilt University.

Fazio-Griffith, L., \& Ballard, M. B. (2016). Transformational learning theory and transformative teaching: A creative strategy for understanding the helping relationship. Journal of Creativity in Mental Health, 11 (2), 225-234.

Giroux, H. (2010). Teachers as transformative intellectuals. In K. Ryan \& J. M. Cooper (Eds.), Kaleidoscope: Contemporary and classic readings in education (pp. 35-40). Belmont, CA: Wadsworth.

Lantolf, J. P. (2011). Integrating sociocultural theory and cognitive linguistics in the second language classroom. In E. Hinkel (Ed.), Handbook of research on second language teaching and learning, Vol. II. (pp. 303-318). New York, NY: Routledge.

Lantolf, J. P., \& Thorne, S. L. (2007). Sociocultural theory and second language learning. In B. van Patten \& J. Williams (Eds.), Theories in second language acquisition (pp. 201-224). Mahwah, NJ: Lawrence Erlbaum.

Maclellan, E. (2015). Updating understandings of 'teaching': Taking account of learners' and teachers' beliefs. Teaching in Higher Education, 20(2), 171-182.

Merriam, S. B. (1998). Qualitative research and case study applications in education: Revised and expanded from "Case study research in education". San Francisco, CA: Jossey-Bass.

Meyers, C., \& Jones, T. B. (1993). Promoting active learning: Strategies for the college classroom. San Francisco, CA: Jossey-Bass.

Mezirow, J. (2000). Learning as transformation: Critical perspectives on a theory in progress. San Francisco, CA: Jossey-Bass.

Michael, J. (2006). Where's the evidence that active learning works? Advances in Physiology Education, 30(4), 159-167. 
Noland, A., \& Richards, K. (2014). The relationship among transformational teaching and student motivation and learning. Journal of Effective Teaching, 14(3), 5-20.

Plough, I. C. (2016). Cultures \& Languages Across the Curriculum: Strengthening intercultural competence and advancing internationalization. Multicultural Education, 23(2), 46-51.

Prince, M. (2004). Does active learning work? A review of the research. Journal of Engineering Education, 93(3), 223-231.

Rifkin, B. (2012). The world language curriculum at the center of postsecondary education. Liberal Education, 98(3), 54-57.

Rosebrough, T. R., \& Leverett, R. G. (2011). Transformational teaching in the information age: Making why and how we teach relevant to students. Alexandria, VA: Association for Supervision and Curriculum Development.

Schunk, D. H., \& Pajares, F. (2009). Self-efficacy theory. In K. R. Wentzel \& A. Wigfield (Eds.), Handbook of motivation at school (pp. 35-54). New York, NY: Routledge.

Shellenbarger, T., Palmer, E. A., Labant, A. L., \& Kuzneski, J. L. (2005). Use of faculty reflection to improve teaching. In M. H. Oermann \& K. T. Heinrich (Eds.), Annual review of nursing education volume 3, 2005: Strategies for teaching, assessment, and program planning (p. 343-358). New York, NY: Springer.

Slavich, G. M. (2006). Transformational teaching. In T. Zinn, B. Saville, \& J. Williams (Eds.), Essays from excellence in teaching: 2005. Washington, DC: American Psychological Association.

Slavich, G. M., \& Zimbardo, P. G. (2012). Transformational teaching: Theoretical underpinnings, basic principles, and core methods. Educational Psychology Review, 24(4), 569-608.

Sullivan, S. S., \& Glanz, J. G. (2009). Supervision that improves teaching and learning: Strategies and techniques (3rd ed.). Thousand Oaks, CA: Sage.

Tahir, K. (2018). Transformational teaching: Pakistani students' perspectives in the English classroom. International Journal of Teaching and Learning in Higher Education, 30(1), 61-69.

Taylor, E. W. (2007). An update of transformative learning theory: A critical review of the empirical research (1999-2005). International Journal of Lifelong Education, 26, 173191.

Telsang, M. T. (2015). Personal transformation from a teacher to a learning facilitator: A case study. In R. Natarajan (Ed.), Proceedings of the International Conference on Transformations in Engineering Education: ICTIEE 2014 (pp. 565-566). New Delhi, India: Springer.

van Merriënboer, J. J. G., \& Sluijsmans, D. M. A. (2008). Toward a synthesis of cognitive load theory, four-component instructional design, and self-directed learning. Educational Psychology Review, 21, 55-66.

Vetter, A. (2012). Teachers as architects of transformation: The change process of an elementary-school teacher in a practitioner research group. Teacher Education Quarterly, 39(1), 27-49.

Yin, R. K. (1994). Discovering the future of the case study method in evaluation research. Evaluation Practice, 15(3), 283-290. 


\section{About the Authors}

Ni-La Lê is a PhD candidate in Linguistics with specialization in First Language Acquisition and Cognitive Science at Michigan State University. She is also an instructor in Linguistics at the HCMC University of Education (Vietnam). Her research interests include the acquisition of different syntactic and semantic properties of noun phrases in Vietnamese and English. In addition, she has collaborated with other researchers in multiple interdisciplinary studies in Psychology and Education.

José Martínez Hinestroza, PhD, is an Assistant Professor in elementary mathematics education at Texas State University. His research interests include teacher education and mathematics teaching and learning in bilingual contexts. Specifically, he focuses on the interactions among mathematical activity and other sociocultural phenomena, such as language and participation. His interdisciplinary research, which he has conducted both in the US and Colombia, has contributed to understanding how teachers and students enact and continuously transform these interactions, and how teachers reconceptualize these interactions in inclusive ways.

Erika B. Kraus is a doctoral candidate in the Department of Forestry at Michigan State University in East Lansing, Michigan. She is broadly interested in how people affect nature. Ms. Kraus is studying human-nature interactions through the ecosystem service science framework, specifically how changes in the biophysical environment affect the provision of cultural ecosystem services in the Mono-Couffo, Republic of Benin, and Michigan, USA. She earned a Master's degree in African and African-American Studies at the University of Kansas in Lawrence, Kansas, during which she also studied classical Arabic.

Azad Hassan is a PhD candidate (ABD) in the School of Planning, Design, and Construction at Michigan State University. Also, he is an assistant lecturer at Nawroz University. He holds M.Sc. in Spatial Planning and Statistics from Duhok University, Iraqi Kurdistan Region. In addition to his urban planning expertise, he is an Arabic Integrate Language Fellow in Residential College in the Arts and Humanities' (RCAH) Cultures and Languages across the Curriculum (CLAC) program.

India C. Plough, PhD, is an Assistant Professor and the Director of the Language Proficiency Program at the Residential College in the Arts and Humanities. India's research interests are in the areas of second language acquisition, language instruction, and test development and validation. She has worked in a variety of contexts from secondary and postsecondary institutions to the non-profit, foundation sector. In addition to giving invited talks in Peru and Greece, India has worked with students, teachers, and administrators in Brazil, China, Greece, Japan, Peru, South Africa, and the U.S. on collaborative projects including learner assessment, teacher training, and program development. 


\section{Appendix SELF-REFLECTION QUESTIONNAIRE}

1. Do you think that the students were engaged during this ILO meeting? If so, please give an example.

2. Were the materials and/or activities connected to students' interests? If so, please give an example.

3. In this meeting did you model an activity for the students? If so, please give an example.

4. Did the more advanced student(s) take the lead and help the less advanced student(s)? If so, please explain.

5. Did the activities in the meeting encourage student collaboration? If so, please give an example.

6. Did students reflect on personal experiences? If so, were your materials and/or activities designed for this purpose? Please give an example.

7. Do you think the students freely expressed their points of view? Please give an example of a topic.

8. Did students introduce topics for discussion that you had not planned? Please give an example.

9. In discussions, did students share their attitudes or feelings toward a cultural issue? If so, what do you attribute this to? The activities? The materials? The individuals?

10. If you answered "yes" to Question 9, did you see a student's attitudes or beliefs change in the course of the discussion? Please give an example.

11. Did students propose strategies for examining an issue or tackling a problem during discussions? Please give an example.

12. Any other observations you want to share (any unexpected events, your solution,...). 